\title{
Short communication: Separation and quantification of caseins and casein macropeptide using ion-exchange chromatography
}

\author{
B. Holland, S. Rahimi Yazdi, G. Ion Titapiccolo, and M. Corredig ${ }^{1}$ \\ Department of Food Science, University of Guelph, Guelph, Ontario, N1G 2W1 Canada
}

\begin{abstract}
The aim of this work was to improve an existing method to separate and quantify the 4 major caseins from milk samples (i.e., containing whey proteins) using ion-exchange chromatography. The separation process was carried out using a mini-preparative cation exchange column (1 or $5 \mathrm{~mL}$ of column volume), using urea acetate as elution buffer at $\mathrm{pH} 3.5$ with a $\mathrm{NaCl}$ gradient. All 4 major caseins were separated, and the purity of each peak was assessed using sodium dodecyl sulfate-PAGE. Purified casein fractions were also added to raw milk to confirm their elution volumes. The quantification was carried out using purified caseins in buffer as well as added directly to fresh skim milk. This method can also be employed to determine the decrease in $k$-casein and the release of the casein-macropeptide during enzymatic hydrolysis using rennet. In this case, the main advantage of using this method is the lack of organic solvents compared with the conventional method for separation of macropeptide (using reversed phase HPLC).
\end{abstract}

Key words: casein, ion exchange chromatography, protein quantification, casein macropeptide

Typical pooled bovine milk consists of approximately $87 \%$ water, $3.9 \%$ milk fat, $3.25 \%$ protein, and $5.5 \%$ other solids, including lactose (Walstra and Jenness, 1984). Of the $3.25 \%$ protein, approximately $80 \%$ is composed of caseins. Caseins are defined as those proteins that coagulate at a $\mathrm{pH}$ of 4.6 , and bovine milk contains 4 major caseins: $\alpha_{\mathrm{S}^{-}}, \alpha_{\mathrm{S} 2}, \beta$-, and $\kappa$-caseins, at concentrations of approximately $10,2.6,9.3$, and 3.3 $\mathrm{mg} / \mathrm{mL}$, respectively (Karman and Van Boekel, 1986). In unaltered milk they are found together with whey proteins. The whey proteins remain soluble at the isoelectric point of the caseins ( $\mathrm{pH} 4.6$ ) and consist principally of $\beta$-lactoglobulin, $\alpha$-lactalbumin, and bovine serum albumin, in a ratio of about 3:1 caseins:whey proteins (Fox and McSweeney, 2003).

Received October 13, 2009.

Accepted November 11, 2009.

${ }^{1}$ Corresponding author: mcorredi@uoguelph.ca
The separation and quantification of caseins from milk has been carried out using various methods over the years, but few are well suited for efficient quantification. The most widely used technique to separate milk proteins is PAGE. This technique can be used to separate all major milk fractions as well as many minor proteins (Ng-Kwai-Hang and Kroeker, 1984; Kim and Jimenez-Flores, 1993). When combined with digital scanning and appropriate software, densitometry can be used to quantify the gel bands. Some of the challenges with the use of electrophoresis for quantification are related to the staining and destaining procedures often resulting in a wide statistical error (Holt and Zeece, 1988).

A more accurate technique for quantification is reverse phase (RP)-HPLC. Several methods have been published using this technique (Léonil et al., 1995; Bobe et al., 1998; Bordin et al., 2001). In most cases, the samples need to be pretreated by acidification to precipitate the whey proteins from the caseins. A centrifugation step needs to be included, and this step has the potential to introduce significant error in the measurements. The RP-HPLC method also requires significant amounts of organic solvents (i.e., acetonitrile) and long buffer gradients (around $50 \mathrm{~min}$ ). Reverse phase-HPLC is currently an established method for the quantification of the amount of casein macropeptide (CMP) released from $\kappa$-casein during the renneting process (van Hooydonk et al., 1984; Lopez-Fandino et al., 1993).

Ion-exchange chromatography is also widely used to isolate milk proteins (Andrews et al., 1985; Hollar et al., 1991). All current methods, however, require the separation of the casein fractions from the whey protein fractions before the sample can be applied to the column. However, these methods have been successfully applied for the preparative separation of caseins and whey proteins.

The objective of our study was to develop an ionexchange chromatography method that could be applied to accurately separate and quantify all major casein fractions from milk samples. The method was also applied to the determination of the amount of ca- 
A

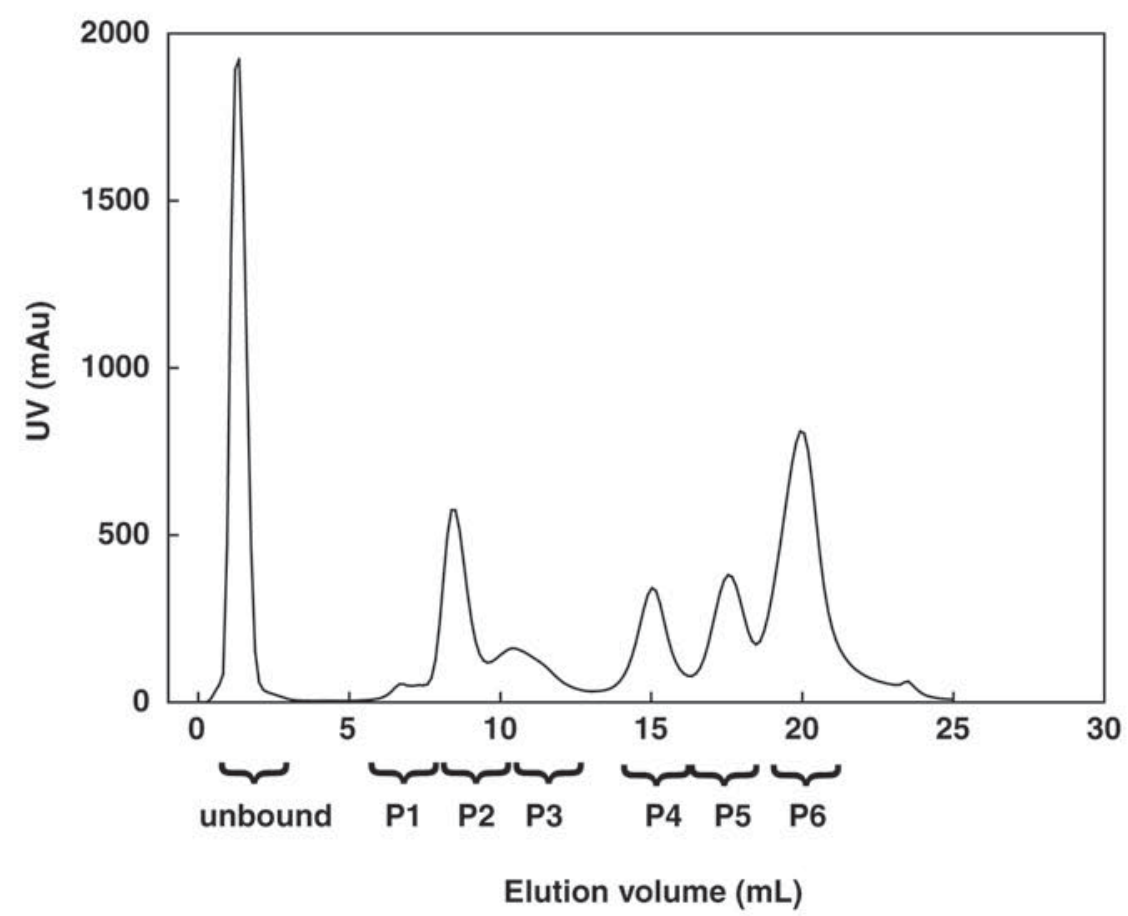

B

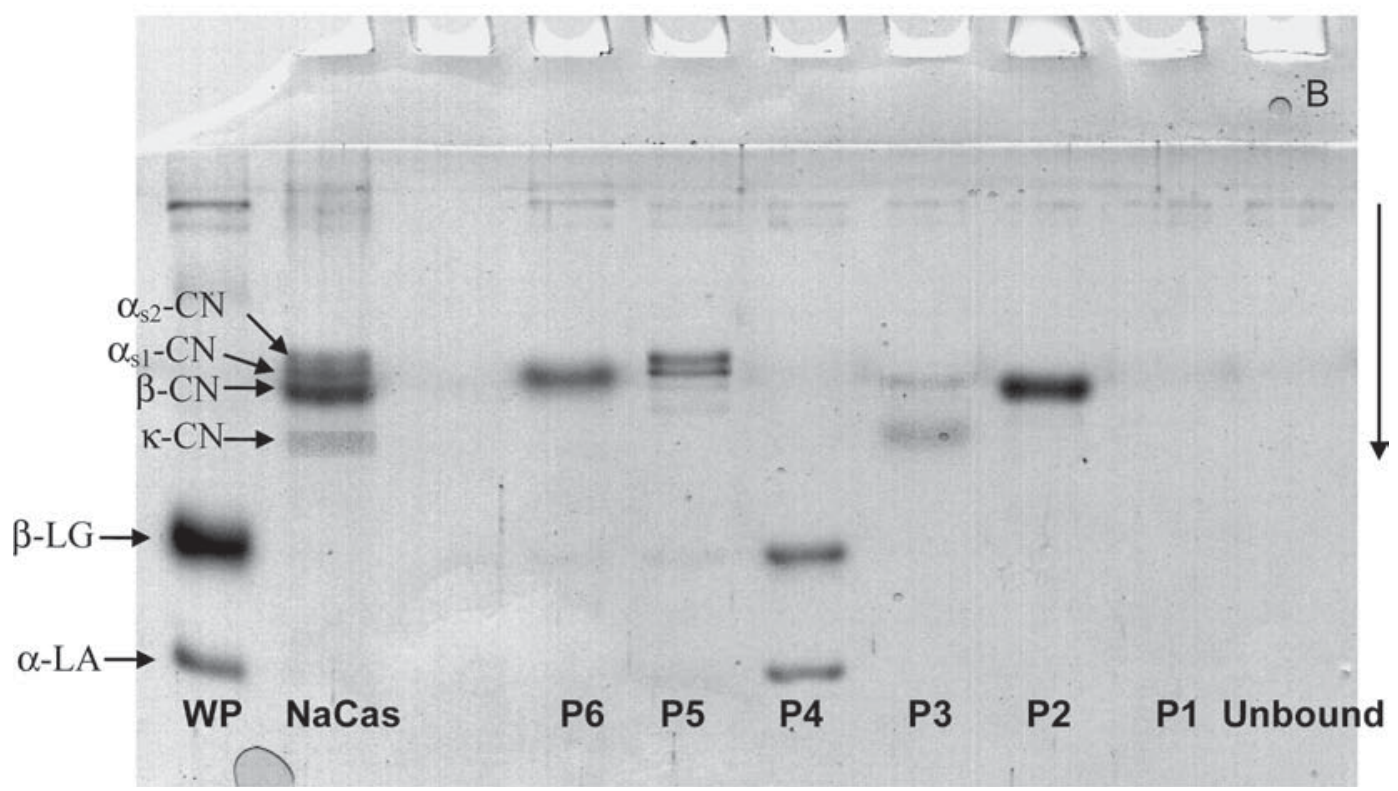

Figure 1. A) Elution chromatogram (data are average of 3 runs) for raw milk and B) SDS-PAGE of the corresponding peaks (P). NaCas = sodium caseinate; $\mathrm{WP}=$ whey protein isolate. Arrow indicates direction of migration.

sein macropeptide (i.e., breakdown of k-casein) during renneting of milk.

Reagents were purchased from Fisher Scientific (Mississauga, Ontario, Canada). Rennet (Chymostar single strength rennet) was donated by Rhodia (Cranbury,
NJ), and pepstatin A was purchased from Fisher Scientific (Pittsburgh, PA). Proteins were isolated and purified as previously reported (Andrews et al., 1985) using a preparative cation exchange column and a gradient of $\mathrm{NaCl}$ in $0.2 M$ sodium acetate and $6 \mathrm{M}$ urea buffer 


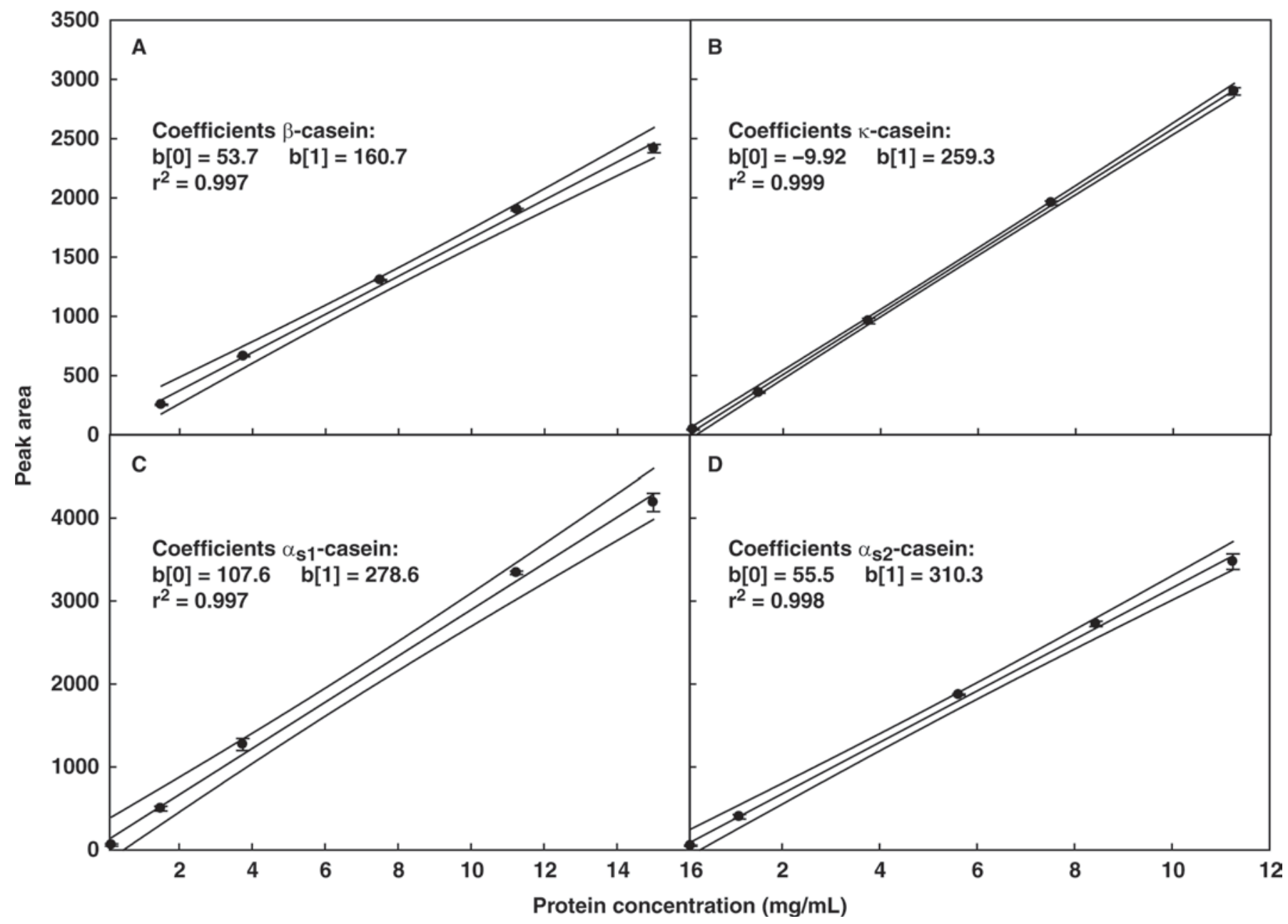

Figure 2. Calibration curves for purified casein fractions resuspended in buffer for A) $\beta$-casein; B) $\kappa$-casein; C) $\alpha_{\mathrm{S} 1^{-}}$-casein; and D) $\alpha_{\mathrm{S} 2^{-c a s e i n}}$. Lines indicate $95 \%$ confidence interval and points are the average of 3 different replicate samples. Regression coefficients b(0) (intercept), b(1) are also shown in the graph. Peak area in $\mathrm{mAU} \cdot \mathrm{mL}$.

at $\mathrm{pH}$ 5.0. The purified proteins were dialyzed, freezedried, and stored in airtight containers at $-20^{\circ} \mathrm{C}$ until use. Skimmed raw milk was obtained from fresh whole milk (Elora Dairy Research Center, Ontario, Canada) after centrifugation at $6,000 \times g$ for $20 \mathrm{~min}$ at $4^{\circ} \mathrm{C}$ using a JA-10 rotor (Beckman J2-21 centrifuge, Beckman Coulter, Mississauga, Canada) and filtration (4 times) through fiberglass filters (Whatman, Fisher Scientific).

A sample buffer consisting of $0.2 \mathrm{M}$ sodium acetate and $6 M$ urea was prepared, and solid samples (i.e., skim milk powder, purified caseins) were added directly to this buffer at the desired concentration. When analyzing liquid samples (e.g., fresh skim milk), aliquots (5 $\mathrm{mL}$ ) were added to $5 \mathrm{~mL}$ of sample buffer, and $3.599 \mathrm{~g}$ of urea and $0.013 \mathrm{~g}$ of sodium acetate were then added. The samples were stirred for $1 \mathrm{~h}$, the $\mathrm{pH}$ was adjusted to 7.0 , and $\beta$-mercaptoethanol $(0.150 \mathrm{~mL})$ was added. The samples were again stirred for $1 \mathrm{~h}$ and the $\mathrm{pH}$ was adjusted to 3.5 with $1 \mathrm{M} \mathrm{HCl}$ and stirred for $5 \mathrm{~min}$. The total volume was then fixed to $15 \mathrm{~mL}$ (if needed) by the addition of MilliQ water (Millipore, Bedford, MA) and stirred for $5 \mathrm{~min}$. The samples were then filtered through a $0.45-\mu \mathrm{m}$ syringe filter (Millex GV, Millipore) before injection.

For quantification of the protein peaks, each of the purified $\alpha_{\mathrm{S}^{-}}, \alpha_{\mathrm{S} 2}, \beta$-, and $\kappa$-caseins was added either directly to sample buffer or to raw milk at a concentration between 0 and $15 \mathrm{mg} / \mathrm{mL}$. For renneting experiments, chymosin was added to raw skim milk at a concentration of 0.018 international milk clotting units $(\mathrm{IMCU}) / \mathrm{mL}$, and each sample was divided in aliquots in different test tubes and incubated at $30^{\circ} \mathrm{C}$. Every 5 min, 2 parallel samples were obtained, one for ion-exchange chromatography and the other for RPHPLC analysis. In the case of samples prepared for ionexchange chromatography, the hydrolysis reaction was 


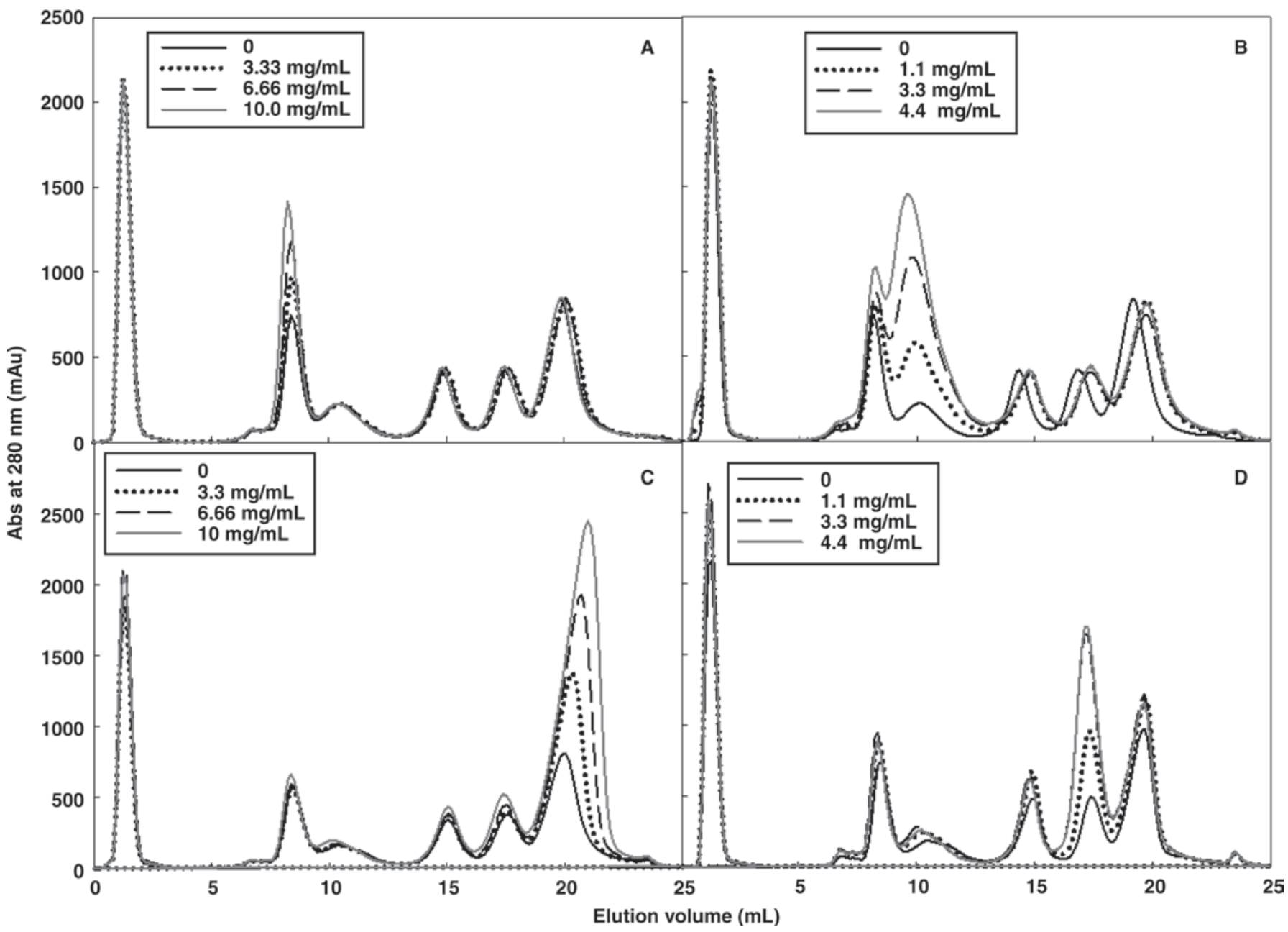

Figure 3. Elution chromatograms of raw skim milk with added amounts of purified A) $\beta$-casein; B) $\kappa$-casein; C) $\alpha_{\mathrm{S1}}$-casein; and D) $\alpha_{\mathrm{S} 2^{-}}$-casein. Abs = absorbance.

stopped by adding pepstatin A to milk (2:100 pepstatin A to milk). The pepstatin A solution was prepared by adding $5 \mathrm{mg}$ in $7.3 \mathrm{~mL}$ of ethanol (96\%). The sample was then treated as indicated before, by addition of sample buffer, solid urea, and sodium acetate, incubation at $\mathrm{pH} 7$ with $\beta$-mercaptoethanol, and $\mathrm{pH}$ adjustment to 3.5. In addition, a parallel sample undergoing hydrolysis was prepared for RP-HPLC. In this case, at certain times from the addition of chymosin, to stop the enzymatic reaction, the sample was diluted $1: 1$ with $4 \%$ trichloroacetic acid. After addition of trichloroacetic acid, the milk was kept in the refrigerator overnight. After equilibration at room temperature, the samples were centrifuged for $15 \mathrm{~min}$ at $4500 \times \mathrm{g}$, using an Eppendorf centrifuge $(5415 \mathrm{D}$, Brinkmann Instruments, Mississauga, Ontario, Canada). The supernatants were removed and filtered through a $0.45-\mu \mathrm{m}$ filter (Millex GV, Millipore).
The HPLC analysis was carried out using a unit (Spectrasystem, Thermal Fisher, Mississauga, Ontario, Canada) consisting of a degasser, pump (P-4000), autosampler, and UV detector (set at $210 \mathrm{~nm}$ ). The supernatant samples were injected $(100 \mu \mathrm{L})$ in a guard column and $\mathrm{C} 2 / \mathrm{C} 18$ column (Pharmacia Biotech $\mu \mathrm{RPC}$ C2/C18 ST 4.6/100, GE Healthcare, Baie D'Urfe, Quebec, Canada). The samples were eluted at $1 \mathrm{~mL} / \mathrm{min}$ with $0.1 \%$ trifluoroacetic acid buffer, with a nonlinear gradient from 0 to $90 \%$ acetonitrile (buffer B). The gradient started with $18 \%$ buffer B and increased from 18 to $39 \%$ buffer B in 35 min, finishing at $100 \%$ buffer $\mathrm{B}$ in $8 \mathrm{~min}$. The total peak areas were estimated using Chromquest software (v. 4.1, Spectrasystem, Thermal Fisher), and the CMP peaks eluted in the range between 10 and $38 \mathrm{~min}$ of the chromatograms. The total peak area for untreated milk (time zero) was subtracted to the peak area of each sample, to calculate the area 


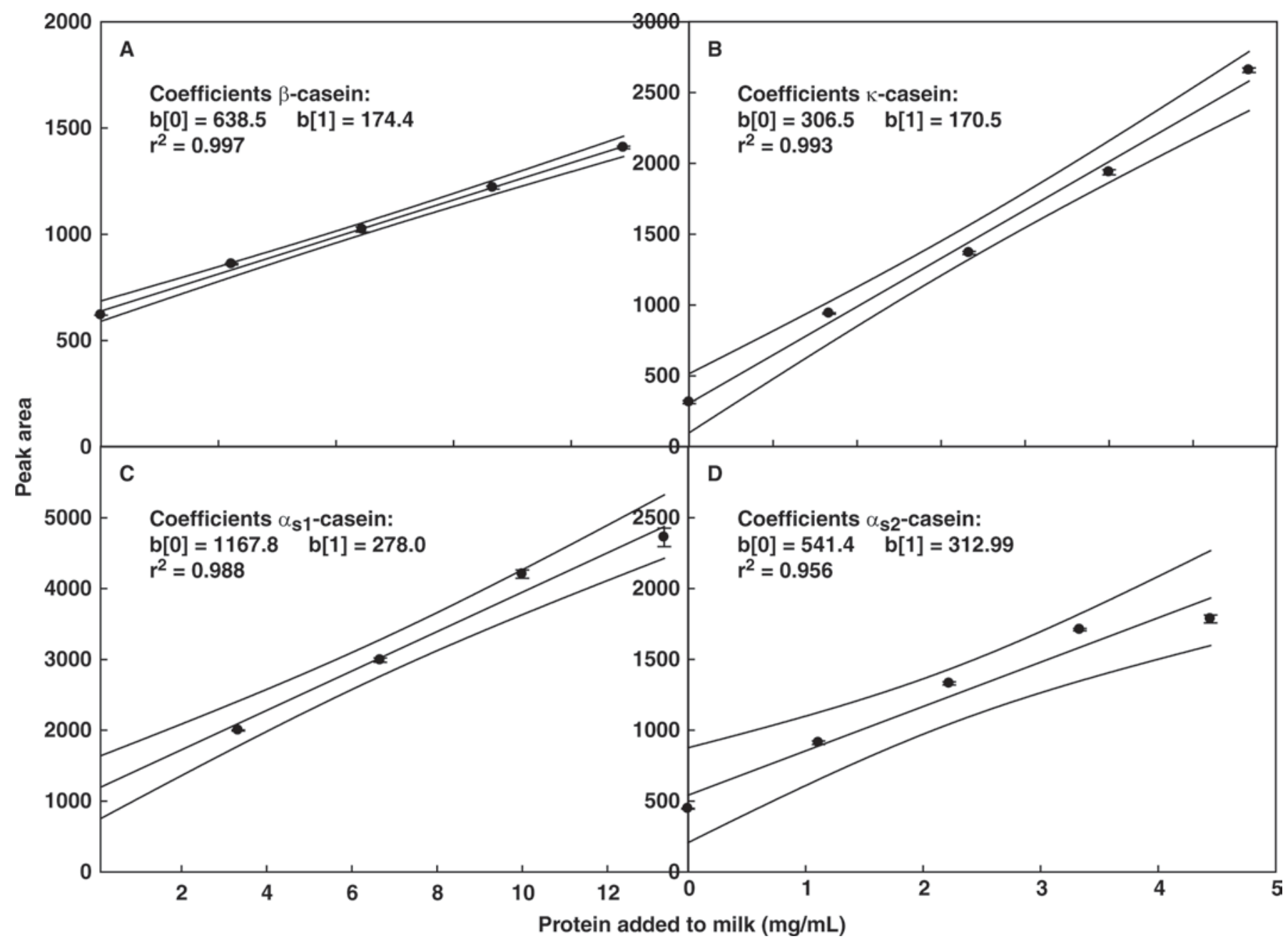

Figure 4. Calibration curves for purified casein fractions added to raw skim milk: A) $\beta$-casein; B) $\kappa$-casein; C) $\alpha_{S 1^{-}}$-casein; and D) $\alpha_{S 2^{-c a s e i n}}$. Lines indicate $95 \%$ confidence interval and points are the average of 3 different replicate samples. Regression coefficients $\mathrm{b}(0)$ (intercept) and $\mathrm{b}(1)$ are also shown in the graph. Peak area in $\mathrm{mAU} \cdot \mathrm{mL}$.

corresponding to the CMP cleaved from $\kappa$-casein. The amount of CMP released as a function of time was then measured relative to the maximum CMP released $(100 \%)$ when the area reached a plateau.

An ÄKTA purifier (900 series, GE Biosciences, Baie d'Urfé, Quebec, Canada), equipped with a UV-900 detector (set at $280 \mathrm{~nm}$ ), a pump (P-900), and a fraction collector was used for the analysis. The samples $(500$ $\mu \mathrm{L})$ were injected in a 1-mL cation exchange HP SP column (GE Biosciences) and eluted at $1 \mathrm{~mL} / \mathrm{min}$ with $0.2 M$ sodium acetate and $6 M$ urea buffer at $\mathrm{pH} 3.5$. An advantage of using $\mathrm{pH} 3.5$ is that the urea breakdown is somewhat limited at this $\mathrm{pH}$ and therefore the formation of carbamate complexes with the $\beta$-casein is also limited. For casein separation (in the absence of CMP peak) the elution was carried out with a gradient of $\mathrm{NaCl}$ consisting of 0 to $0.145 \mathrm{M} \mathrm{NaCl}$ in 4 column volumes $(\mathbf{C V}), 0.145$ to $0.16 M$ in $5 \mathrm{CV}, 0.16$ to 0.23 $M$ in $2 \mathrm{CV}, 0.23$ to $0.31 M$ in $3 \mathrm{CV}, 0.31$ to $0.40 M$ in $2 \mathrm{CV}, 0.40$ to $0.50 \mathrm{M}$ in $2 \mathrm{CV}$, hold at $0.50 \mathrm{M}$ for 2 $\mathrm{CV}$, and then step to $1.00 \mathrm{M} \mathrm{NaCl}$ in $1 \mathrm{CV}$ and hold for $3 \mathrm{CV}$. When CMP was present in the samples, for a better elution of $\kappa$-casein from the para- $\kappa$-casein peak, the gradient applied was as follows: 0 to $0.145 \mathrm{M} \mathrm{NaCl}$ in $6 \mathrm{CV}, 0.145$ to $0.16 \mathrm{M}$ in $10 \mathrm{CV}, 0.16$ to $0.23 \mathrm{M}$ in $9 \mathrm{CV}, 0.23$ to $0.5 \mathrm{M}$ in $1 \mathrm{CV}$, followed by $1 \mathrm{CV}$ at 0.1 $M \mathrm{NaCl}$.

The elution chromatogram of skim milk after elution with the SP-cation exchange column showed 6 main peaks and an unbound peak. Figure 1 depicts the separation of raw milk using a nonlinear gradient of $\mathrm{NaCl}$. It is important to note that in the present experiments the elution volume also corresponds to the column volume $(1 \mathrm{~mL})$. All milk proteins eluted between 0.14 and 


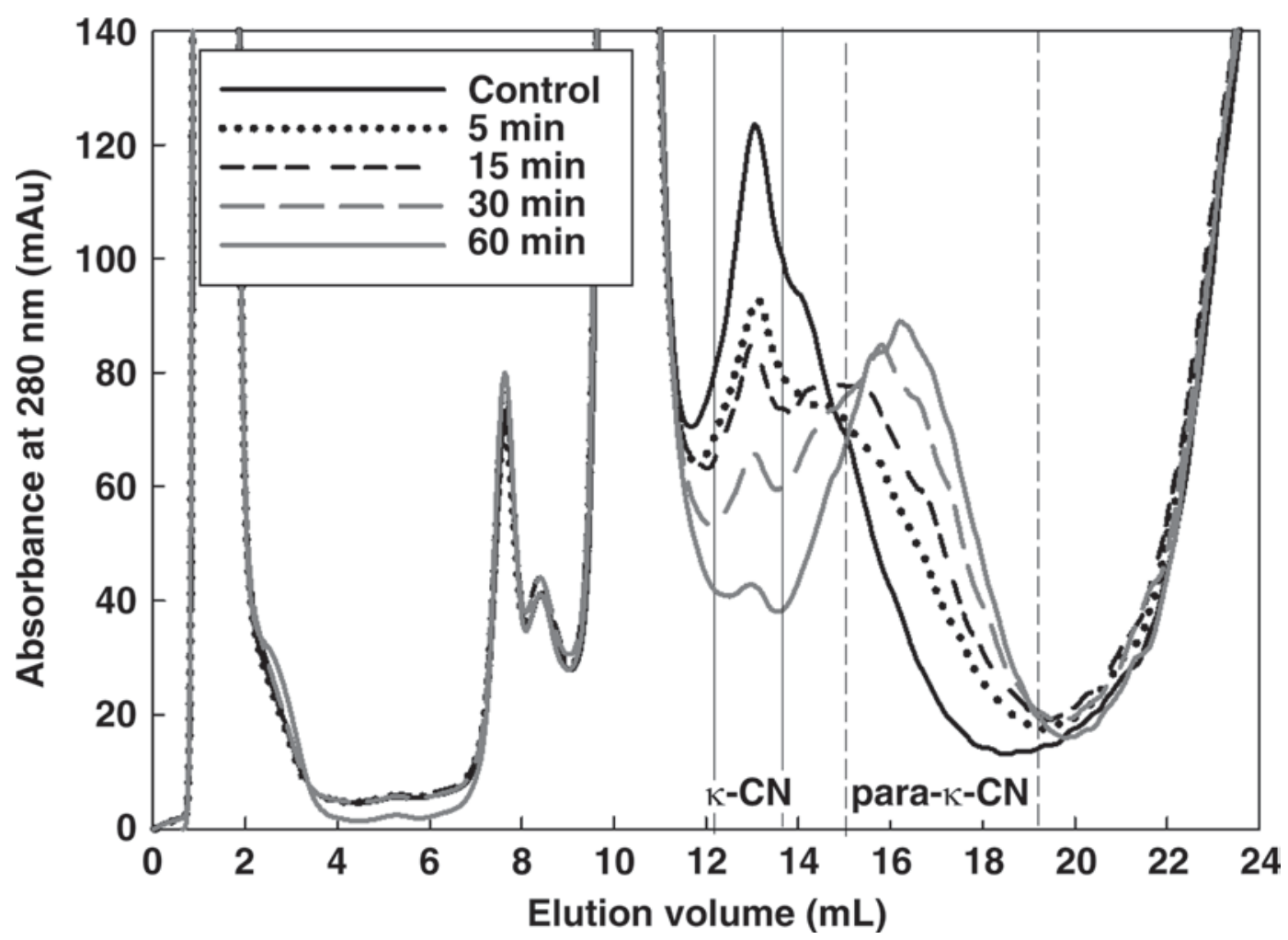

Figure 5. Elution chromatograms for milk treated with chymosin and incubated for different times.

$0.37 M \mathrm{NaCl}$, using $6 \mathrm{M}$ urea at $\mathrm{pH}$ 3.5. Each peak was collected and analyzed by SDS-PAGE to identify the major protein species present in the peaks (Figure 1B). The unbound fraction did not contain detectable amounts of polypeptides. Similarly to the unbound fraction, the fraction collected in the first peak, eluting at about $6.8 \mathrm{~mL}$, did not show measurable amounts of proteins. However, previous work using a similar column and $\mathrm{pH} 5$ urea buffer showed an early peak eluting $\gamma$-casein (Andrews et al., 1985). Peak 2, eluting at $8.4 \mathrm{~mL}$, was $\beta$-casein. Immediately after, and not fully resolved, was a smaller peak eluting at 10.3 $\mathrm{mL}$. This peak contained $\kappa$-casein, as shown by SDSPAGE analysis. Peak 3 also contained some $\beta$-casein, most likely because of the poor cut-off between the 2 peaks. The peak eluting at $14.6 \mathrm{~mL}$ (peak 4) was well separated and contained both major whey proteins ( $\alpha$-lactalbumin and $\beta$-lactoglobulin). It was concluded that by eluting the milk proteins at $\mathrm{pH} 3.5$ it was possible to separate the whey proteins from the caseins using chromatography without the use of a sample preparation step. The 2 major peaks eluting at 17.3 and $19.7 \mathrm{~mL}$, indicated as peaks 5 and 6 , corresponded to $\alpha_{S^{-}}$and $\alpha_{S^{-}}$caseins, respectively. Although peak 5 contained traces of $\alpha_{S 1}$-casein, peak 6 showed the presence of a single $\alpha_{\mathrm{S} 1}$-casein band.
Figure 2 summarizes the results of linear regression for the 4 caseins when quantified using pure protein fractions resuspended in sample buffer, in a range of concentrations between 0 and $14 \mathrm{mg} / \mathrm{mL}$. A linear relationship (with a coefficient of determination, $\mathrm{R}^{2}$, of 0.99 for all 4 caseins) was found between the concentration of protein present in solution and the peak area. Because peak resolution could not be achieved in all cases, to confirm the identification carried out by SDS-PAGE electrophoresis, and to better evaluate if a linear relation could still be established in milk systems, various amounts of purified caseins were added to raw milk to quantify the peak areas under less-than-ideal conditions.

Figure 3 depicts the changes in the chromatograms for raw milk samples containing additional amounts of caseins. In the case of $\kappa$-casein, an increase in the $\beta$-casein peak was noted: the $\kappa$-casein peak eluted as a shoulder on the $\beta$-casein peak. In all the other caseins, $\alpha_{\mathrm{S} 1}, \alpha_{\mathrm{S} 2}$, and $\beta$-casein, an increase in the amount of purified protein added was directly related to the growth of the peak area corresponding to the eluted protein growth in $\beta$-casein. The quantification curves shown in Figure 4 clearly confirm these observations. Within the protein amounts tested, there was a linear relation between the protein concentration and the area mea- 


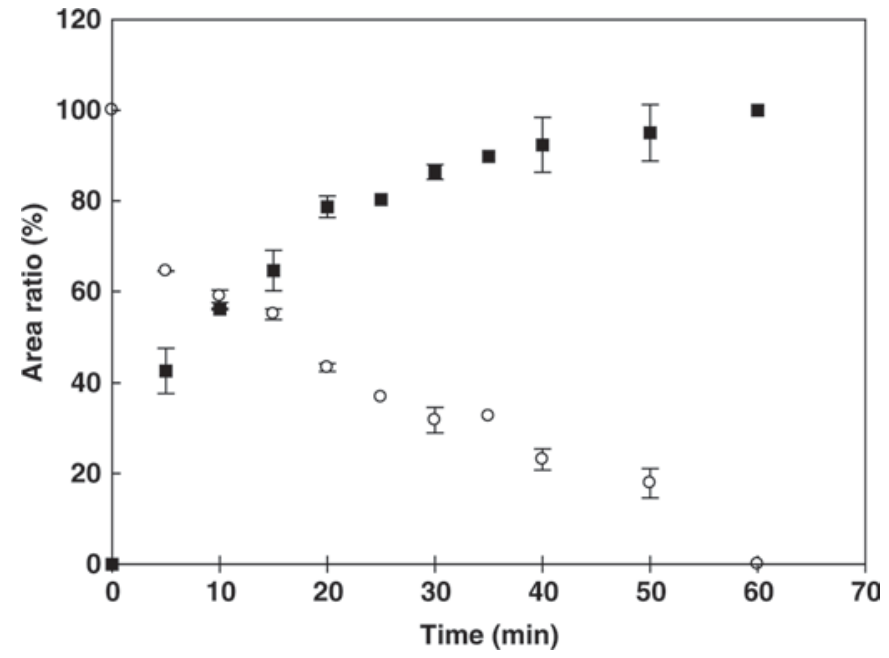

Figure 6. Decrease in $\kappa$-casein area compared with the initial area $(\bigcirc)$ and increase in para- $\kappa$-casein released $(\boldsymbol{\square})$, as a function of time of hydrolysis after addition of chymosin.

sured. The slopes of the linear regressions were, within experimental error, within those measured in buffer samples, apart from $\kappa$-casein. In this case, at high concentrations there would be an underestimation of the $\kappa$-casein peak; however, this underestimation would not occur in the concentration range normally found in milk samples, where the 2 calibration curves overlap. There was also very little deviation between injections in the same set of runs and those of other runs. All deviations were below $10 \%$ of the original.

During renneting of casein micelles, the enzyme chymosin acts specifically on $\kappa$-casein, causing the release of CMP in solution from the casein micelles. The separation method outlined above was applied to milk samples subjected to hydrolysis. The decrease in the amount of $\kappa$-casein was followed as a function of time of hydrolysis. A different $\mathrm{NaCl}$ gradient was employed in this case, as focus was on the $\kappa$-casein peak. Figure 5 illustrates the changes in the elution for samples incubated for various times with chymosin. While the $\kappa$-casein peak decreased with time, a second peak eluted between 14 and $20 \mathrm{~mL}$. This peak corresponded to the para- $\kappa$-casein (existing in a 1:1 ratio with the CMP in solution) and eluted as a shoulder on the $\kappa$-casein peak. For this reason, the areas were quantified by using a cut-off at $13.6 \mathrm{~mL}$ for $\kappa$-casein, with a subsequent peak for CMP between 13.6 and $19.8 \mathrm{~mL}$. Figure 6 illustrates the amount of para-k-casein measured over time (calculated as $100 \%$ of the curve at maximum time of enzymatic incubation), and the amount of $\kappa$-casein, as the area percentage of the original area. While CMP increased, the $\kappa$-casein area decreased over time.

The amount of CMP released was also quantified in a parallel sample using RP-HPLC. The amount of CMP released relative to the final amount at plateau is shown in Figure 7. The amount of CMP released measured by HPLC is compared in Figure 7 to the amount of CMP released measured by ion-exchange chromatography, as well as to the decrease in the $\kappa$-casein (as $1-\kappa$-casein), again measured by ion-exchange chromatography. The values measured with the 2 techniques generally agreed, although a higher amount of CMP was quantified by ion-exchange chromatography at the beginning stages of the reaction. This could be caused by the use of pepstatin A to stop the reaction, and the inhibitor may not cause immediate cessation of the enzyme's activity. At the longer times, agreement was noted between the 2 methods in the measurement of CMP. On the other hand, at the longer times, there seemed to be a residual amount of $\kappa$-casein present in the samples when measured by ion-exchange chromatography (about 10\%), most likely caused by a carry-over of $\beta$-casein into the $\kappa$-casein peak.

The use of ion-exchange chromatography with a cation exchange column has the ability to separate and quantify the 4 major casein fractions. The advantage of this method over others is that it is able to complete this separation from raw or processed dry or liquid milk samples without the need to first separate caseins from whey proteins by some form of precipitation. However, there seems to be general agreement between the ionexchange separation and the RP-HPLC, and we suggest that ion-exchange chromatography may also be an alternative to measurements of CMP release from micelles during renneting.

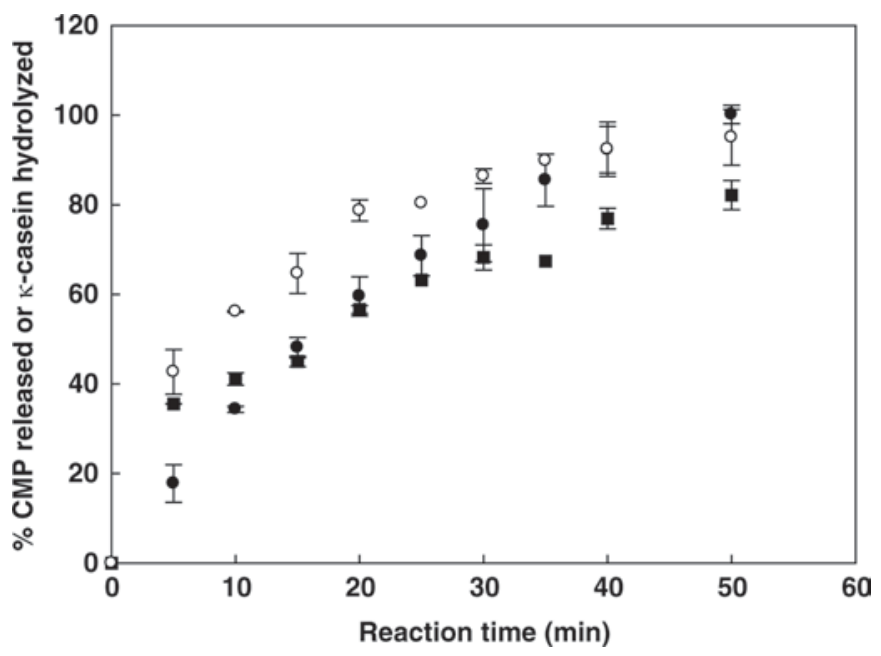

Figure 7. Amount of casein macropeptide (CMP) released during chymosin hydrolysis. $\bullet=$ para- $\kappa$-casein area percentage measured using reverse phase-HPLC; $\bigcirc=$ CMP area percentage measured using ion-exchange chromatography; $=$ amount of $\kappa$-casein hydrolyzed $(1-\kappa$-casein initial area). 


\section{REFERENCES}

Andrews, A. T., M. D. Taylor, and A. J. Owen. 1985. Rapid analysis of bovine milk proteins by fast protein liquid chromatography. J. Chromatogr. A 348:177-185.

Bobe, G., D. C. Beitz, A. E. Freeman, and G. L. Lindberg. 1998 Separation and quantification of bovine milk proteins by reversedphase high-performance liquid chromatography. J. Agric. Food Chem. 46:458-463.

Bordin, G., F. C. Raposo, B. de la Calle, and A. R. Rodriguez. 2001. Identification and quantification of major bovine milk proteins by liquid chromatography. J. Chromatogr. A. 98:63-76.

Fox, P. F., and P. L. H. McSweeney. 2003. Advanced Dairy Chemistry. Vol 1: Proteins. Part A. 3rd ed. Springer, New York, NY.

Hollar, C. M., A. J. R. Law, D. G. Dalgleish, and R. J. Brown. 1991 Separation of major casein fractions using cation-exchange fast protein liquid chromatography. J. Dairy Sci. 74:2403-2409.

Holt, D. L., and M. G. Zeece. 1988. Two-dimensional electrophoresis of bovine milk proteins. J. Dairy Sci. 71:2044-2050.

Kim, H.-H. Y., and R. Jimenez-Florez. 1993. Two-dimensional analysis of skim milk proteins using preparative isoelectric focusing followed by polyacrylamide gel electrophoresis. J. Food Biochem. 16:307321
Karman, A. H., and M. A. J. S. Van Boekel. 1986. Evaluation of the Kjeldahl factor for conversion of the nitrogen content of milk and milk products to protein content. Neth. Milk Dairy J. 40:315336.

Léonil, J., D. Mollé, F. Gaucheron, P. Arpino, P. Guénot, and J. L. Maubois. 1995. Analysis of major bovine milk proteins by online high-performance liquid chromatography and electrospray ionization mass spectrometry. Lait 75:193-210.

Lopez-Fandino, R., M. I. Acedo, and M. Ramos. 1993. Comparative study by HPLC of caseinomacropeptides from cows', ewes' and goats' milk. J. Dairy Res. 60:117-121.

Ng-Kwai-Hang, K. F., and E. M. Kroeker. 1984. Rapid separation and quantification of major milk caseins and whey proteins of bovine milk by polyacrylamide gel electrophoresis. J. Dairy Sci. 67:3052-3056.

van Hooydonk, A. C. M., C. Olieman, and H. G. Hagedoorn. 1984 Kinetics of the chymosin catalyzed proteolysis of $\kappa$-casein in milk. Neth. Milk Dairy J. 37:207-222.

Walstra, P., and R. Jenness. 1984. Dairy Chemistry and Physics. Wiley Scientific, New York, NY. 